\title{
SHARP BOUNDS FOR $m$-LINEAR HILBERT-TYPE OPERATORS ON THE WEIGHTED MORREY SPACES
}

\author{
TSERENDORJ BATBOLD AND YOSHIHIRO SAWANO
}

Abstract. On the product of $m$ weighted Morrey spaces, some $m$-linear operators are shown to be bounded. The operator norm is calculated explicitly. It may be interesting to compare the results for the Hardy operator and the ones for the Hardy-Littlewood maximal operator. In the end of this article, some concrete examples are presented.

Mathematics subject classification (2010): Primary 42B25; Secondary 26D15.

Keywords and phrases: Sharp bound, $m$-linear Hilbert operator, Hardy operator, Morrey space, HardyLittlewood maximal operator, Fefferman-Phong inequality.

\section{REFERENCES}

[1] V. Adiyasuren, Ts. Batbold, M. Krnić, On several new Hilbert-type inequalities involving means operators, Acta Math. Sin. (Engl. Ser.) 29 (2013), 1493-1514.

[2] V. AdiYASUREN, Ts. BATBOLD, M. KRnić, Hilbert-type inequalities involving differential operators, the best constants, and applications, Math. Inequal. Appl. 18 (2015), 111-124.

[3] Á. BÉNYI AND T. OH, Best constants for certain multilinear integral operators, J. Inequal. Appl. 2006, 1-12 (2006) (Article ID 28582).

[4] V. I. BuREnkov, P. JAIn And T. V. TARARYkova, On boundedness of the Hardy operator in Morrey-type spaces, Eurasian Math. J. 2 (2011), no. 1, 52-80.

[5] ERIDANI, H. GUNAWAN AND M. I. UTOYO, A characterization for fractional integral operators on generalized Morrey spaces, Anal. Theory Appl. 28 (2012), no. 3, 263-267.

[6] Z. W. FU, $\lambda$-central BMO estimates for commutators of $N$-dimensional Hardy operators, J. Inequal. Pure Appl. Math. 9 (2008), no. 4, Article 111, 5 pp.

[7] Z. Fu, L. GRAFAKOS, S. LU AND F. ZHAO, Sharp bounds for $m$-linear Hardy and Hilbert operators, Houston J. Math. 38 (2012) 225-243.

[8] Z. W. FU AND Y. LIN, $\lambda$-central BMO estimates for commutators of higher-dimensional fractional Hardy operators (Chinese), Acta Math. Sinica (Chin. Ser.) 53 (2010), no. 5, 925-932.

[9] Z. W. FU AND S. Z. LU, Weighted Hardy operators and commutators on Morrey spaces, Front. Math. China 5 (2010), no. 3, 531-539.

[10] Z. W. FU, S. Z. LU AND F. Y. ZhaO, Commutators of n-dimensional rough Hardy operators, Sci. China Math. 54 (2011), no. 1, 95-104.

[11] S. Gala, A. M. Ragusa, Y. SaWAno, And H. TANaKa, Uniqueness criterion of weak solutions for the dissipative quasi-geostrophic equations in Orlicz-Morrey spaces, Appl. Anal. 93 (2014), no. 2, 356-368.

[12] S. Gala, Y. SaWAno, And H. TANAKA, A new Beale-Kato-Majda criteria for the $3 D$ magnetomicropolar fluid equations in the Orlicz-Morrey space, Math. Methods Appl. Sci. 35 (2012), no. 11, 1321-1334.

[13] S. Gala, Y. Sawano And H. Tanaka, On the uniqueness of weak solutions of the $3 D$ MHD equations in the Orlicz-Morrey space, Appl. Anal. 92 (2013), no. 4, 776-783.

[14] G. GAO, Boundedness for commutators of $n$-dimensional rough Hardy operators on Morrey-Herz spaces, Comput. Math. Appl. 64 (2012), no. 4, 544-549.

[15] G. L. GAo AND X. YU, Some estimates for the generalized Hardy operators on some function spaces (Chinese), Acta Math. Sinica (Chin. Ser.) 55 (2012), no. 6, 1101-1110. 
[16] G. H. Hardy, J. E. Littlewood, G. Pólya, Inequalities, Cambridge University Press Cambridge, 1952.

[17] A. Kalybay, On boundedness of the conjugate multidimensional Hardy operator from a Lebesgue space to a local Morrey-type space, Int. J. Math. Anal. (Ruse) 8 (2014), no. 9-12, 539-553.

[18] M. Krnić, J. PeČArić, I. Perić, P. Vuković, Recent Advances in Hilbert-type Inequalities, Element, Zagreb, 2012.

[19] S. Z. LU And F. Y. Zhao, CBMO estimates for multilinear Hardy operators, Acta Math. Sin. (Engl. Ser.) 26 (2010), no. 7, 1245-1254.

[20] D. Luk Kassen, D. E. Persson And S. G. SAmKo, Some sharp inequalities for integral operators with homogeneous kernel, J. Inequal. Appl. 2016: 114.

[21] P. OLSEn, Fractional integration, Morrey spaces and Schrödinger equation, Comm. Partial Differential Equations, 20 (1995), 2005-2055.

[22] N. S AmKo, Weighted Hardy and potential operators in Morrey spaces, J. Funct. Spaces Appl. 2012, Art. ID 678171, $21 \mathrm{pp}$.

[23] N. S Amко, Weighted Hardy operators in the local generalized vanishing Morrey spaces, Positivity 17 (2013), no. 3, 683-706.

[24] Y. SAWANO, S. SUGANO AND H. TANAKA, Generalized fractional integral operators and fractional maximal operators in the framework of Morrey spaces, Trans. Amer. Math. Soc. 363 (2011), no. 12, 6481-6503.

[25] Y. SaWAno, S. Sugano And H. TANAKa, Olsen's inequality and its applications to Schrödinger equations, Suurikaiseki Kǒkyǔroku Bessatsu B26, (2011) 51-80.

[26] Y. Sawano, S. SugAno And H. TANAKa, Orlicz-Morrey spaces and fractional operators, Potential Anal., 36, no. 4 (2012), 517-556.

[27] I. Sihwaningrum, H. P. SuRYaWAn AND H. Gunawan, Fractional integral operators and Olsen inequalities on non-homogeneous spaces, Aust. J. Math. Anal. Appl. 7 (2010), no. 1, Art. 14, 6 pp.

[28] S. SugAno, Some inequalities for generalized fractional integral operators on generalized Morrey spaces, Math. Inequal. Appl., 14 (2011), no. 4, 849-865.

[29] S. Sugano And H. TANAKA, Boundedness of fractional integral operators on generalized Morrey spaces, Sci. Math. Jpn., 58 (2003), no. 3, 531-540 (Sci. Math. Jpn. Online 8 (2003), 233-242).

[30] H. TANaKa, Morrey spaces and fractional operators, J. Aust. Math. Soc. 88 (2010), no. 2, 247-259.

[31] C. Q. TANG, F. XUE AND Y. Zhou, Commutators of weighted Hardy operators on Herz-type spaces, Ann. Polon. Math. 101 (2011), no. 3, 267-273.

[32] T. D. TRAN, Generalized weighted Hardy-Cesaro operators and their commutators on weighted Morrey spaces, J. Math. Anal. Appl. 412 (2014), no. 2, 1025-1035.

[33] M. I. UTOYO, T. Nus ANTARA AND B. S. Widodo, Fractional integral operator and Olsen inequality in the non-homogeneous classic Morrey space, Int. J. Math. Anal. (Ruse) 6 (2012), no. 29-32, 1501-1511. 